\title{
International Journal of Zoological
Investigations \\ Effect of Aqueous and Ethanolic Extracts of Papaya Seeds on Duodenal Mucosa of Rats
}

\author{
Aisha D. Alalwani \\ Department of Biology, Faculty of Sciences, University of Jeddah, Saudi Arabia
}

Received: $8^{\text {th }}$ August, 2019

Accepted: $10^{\text {th }}$ September, 2019

https://doi.org/10.33745/ijzi.2019.v05i02.001

\begin{abstract}
Papaya and its seeds are considered important as traditional treatments in Saudi Arabia. This study investigated the effects of aqueous and ethanolic extracts of papaya seeds and their effectiveness on the duodenal mucosa tissues of rats. Twenty-four male rats (Rattus norvegicus) were randomly divided into three numerically equal groups (A,B, and C). Group A, the control group, received daily an oral dose of distilled water. Groups B and C were treated with different extracts (aqueous and ethanolic) of papaya seeds with a daily oral dose of $1 \mathrm{ml} / \mathrm{kg}$ bw for 4 weeks. Groups B and C received aqueous extract and ethanolic extract of papaya seeds, respectively. The results showed different histological changes in the duodenal mucosa of treated animals depending on the extract administered. Group B showed enormous number of microvilli which increased the surface area, mucin filled glycocalyx of enterocytes and goblet cells, Golgi apparatus adjacent to the mucin granules with plentiful rough endoplasmic reticulum, and mitochondria which were particularly abundant within enterocytes. Group C showed no difference in the shape, size and number of the microvilli, some of the microvilli appeared to be swollen and joint together. In the goblet cells opening into the lumen, there were only a few electron-dense mucous granules. The cytoplasm was found containing dilated rough endoplasmic reticulum cisternae and lymphocytes were found in the intercellular clefts between enterocytes.
\end{abstract}

Keywords: Carica papaya, Duodenum, Ultrastructure, Histology

Citation: Aisha D. Alalwani: Effect of aqueous and ethanolic extracts of papaya seeds on duodenal mucosa of rats. Intern. J. Zool. Invest. 5 (2): 01-11, 2019. https://doi.org/10.33745/ijzi.2019.v05i02.001

\section{Introduction}

Carica papaya (C. papaya, family Caricarceae, papaya) is referred to as Bbaz in southern Saudi Arabia. It is one of the most economical and popular plants in the world (Ong et al., 2011). It is a green-colored fruit with yellow pulp and black seeds. Papaya plants are widely found in South America, the Arabian Peninsula, Bahrain, and Morocco. Bbaz or papaya fruit is rich in vitamins $A, C$ and $E$ in addition to vitamins $\mathrm{B}_{6}$ and $\mathrm{B}_{1}$, riboflavin, calcium, iron, and potassium. It increases the activity of digestive enzymes, is a powerful 
antioxidant, and is rich in fiber, which indicate its potential benefits in patients with colon disorders (Anaga and Onehi, 2010). Moreover, it contains the papain enzyme, carpain alkaloids, pseudocarpain, carposide, saponins, glicoside, sucrose, and levulose (Wabo et al., 2010). Papaya has been used empirically as meals or as a treatment for urinary tract disturbance, kidney stones, stomachache, hypertension, analgesia, diarrhea, and dysentery (Hasimun et al., 2014).

Papaya assists in digestion as it contains the papain enzyme, which helps digest proteins. The nutrients provided by papaya (beta-carotene, folic acid, and vitamins) decrease the risk of colon cancer. These nutrients protect against colon cell DNA damage and their use is consequently endorsed for those who are at risk of colon cancer (Akah et al., 2002).

The fibers inside the papaya helps alleviate intestinal disorders in human. Betacarotene and vitamins A, B, C, and E are very effective antioxidants against the oxidation of cholesterol(Wallace, 2008). Cholesterol binds to the arteries when oxidized and forms a layer that blocks the arteries to cause a coronary heart attack. The effect of vitamins $C$ and $\mathrm{E}$ on the oxidation of LDL cholesterol is stronger in the presence of an enzyme called paraoxonase, which prevents the oxidation of cholesterol (LDL cholesterol and HDL cholesterol).

Papaya is rich in vitamin A; therefore Its consumption is encouraged in smokers. Benzo[a]pyrene in cigarettes eliminates vitamin A in the body. Papaya consumption reduces inflammation and lung diseases (Owoyele et al., 2008). Beta-carotene and vitamins $A$ and $C$ in papaya aid the functioning of the immune system and consequently, its consumption is also encouraged in people with ear infections and cold and flu. Moreover, the beta-carotene and vitamins $\mathrm{C}$ and $\mathrm{E}$ in papaya have a powerful action against infections. This is noticeable in people with hypersensitivities (Jason et al., 2001).

In the present study we have investigated the effects of aqueous and ethanolic extracts of papaya seeds on the histological structure of duodenum of rats.

\section{Materials and Methods}

\section{Preparation of papaya seed extract}

C. papaya was collected from Danube hypermarket of Jeddah city. The plant was deposited for diagnosis and authentication to the herbarium unit of the Department of Plant Biology, Science College of Jeddah University. Then black seeds were collected in a clean dry metal plate. The papaya seeds were air-dried on a laboratory bench for 14 days, and then pulverized into a coarse powder using a hammer mill.

The aqueous (water) extract was prepared by soaking $100 \mathrm{~g}$ of the above papaya seed powder in $500 \mathrm{ml}$ distilled water for $24 \mathrm{~h}$. Then the extract was filtered using Whatman No.1 filter paper. The filtrate was stored in a refrigerator at $4 \mathrm{C}$.

The ethanolic extract was prepared by soaking $100 \mathrm{~g}$ of the papaya seed powder in $500 \mathrm{ml}$ of ethyl alcohol with stirring for $24 \mathrm{~h}$. Then the extract was filtered using Whatman No. 1 filter paper and the filtrate was stored in a refrigerator at $4 \mathrm{C}$.

\section{Animals}

In this study 24 white male rats (Rattus norvegicus, bw 190-196 g) were used for the 
experiments. The rats were housed in metallic cages at King Fahad Center for Medical Research, Saudi Arabia. They were kept under standard laboratory conditions with $12 \mathrm{~h}$ light and $12 \mathrm{~h}$ dark cycle and fed with balanced meals and water ad libitum. The rats were cared for in accordance with all guidelines framed by King Fahad Centre for Medical Research for the use and care of experimental animals (A-02-J-008).

\section{Experimental design}

Twenty-four male rats were divided into three numerically equal groups. Group A served as the control and received daily an oral dose of distilled water. Group B and group C were given aqueous and ethanolic extracts of $C$. papaya seeds with a daily oral dose of $1 \mathrm{ml} / \mathrm{kg}$ bw, respectively. The extracts were administered orally once per day for 4 weeks. At the end of the experiment all rats were anesthetized and duodenum was extirpated and quickly fixed in natural $10 \%$ buffered formalin for light microscopy. All rats were weighed at the beginning of the experiment and at 1, 23 and 4 week.

\section{Histological study}

The duodenum was washed well with saline before tissue samples were fixed in the $10 \%$ formalin solution. The fixed tissues were processed by routine paraffin method, sections were cut at $5 \mu \mathrm{m}$ and stained with hematoxylin and eosin. Few sections were stained with polysaccharides and Periodic acid-Schiff (PAS) method to analyze the interaction with the neutral polysaccharides in accordance with Bancroft and Stevens technique.

\section{Ultrastructural study}

For electron microscopic studies, small pieces were fixed in glutaraldehyde mixture. Then these tissues were washed with sodium cacodylate. Secondary fixation of tissues was done with osmium tetraoxide. After dehydration the tissues were embedded in epoxy resin. The sections were cut at 1-0.5 $\mu \mathrm{m}$ and stained with pyrotechnic uranyl acetate and lead citrate and examined by electron microscope at King Fahd Center for Medical Research.

\section{Statistical analysis}

Data are expressed as mean \pm standard error. The total body weight of both experimental and control animals was calculated using tTest (SPSS 16.0).

\section{Results}

Body weight

The body weight from control and treated rats are presented in Table 1 . The weight of rats treated with the aqueous and ethanolic extracts of papaya seeds increases gradually to $220.40 \pm 0.53 \mathrm{~g}$ and $217.19 \pm 0.71 \mathrm{~g}$, respectively at the end of the experiment. Moreover, the control animals also show an increase in the body weight to $219.22 \pm 0.5 \mathrm{~g}$. The body weight of group B and group C exhibit no significant difference when compared to body weight of control rats.

\section{Histological and Ultrastructural studies}

The normal structure of the mucosa of the duodenum of control rats (group A) is composed of the usual three layers: simple columnar epithelium, lamina propria, and muscularis mucosae. The simple columnar epithelium covering the villi and surface of the 
Table 1: Body weight of control and papaya seed extract treated rats

\begin{tabular}{|c|c|c|c|c|c|}
\hline Groups & \multicolumn{5}{|c|}{ Body Weight (g) } \\
\hline & Zero Day & $\mathbf{1}^{\text {st }}$ week & $\mathbf{2}^{\text {nd }}$ week & $\mathbf{3}^{\text {rd }}$ week & $\mathbf{4}^{\text {th }}$ week \\
\hline Group A & $194.81 \pm 1.06$ & $205.81 \pm 0.25$ & $210.43 \pm 0.45$ & $217.33 \pm 1.06$ & $219.22 \pm 0.50$ \\
\hline Group B & $193.23 \pm 0.90$ & $204.89 \pm 0.82$ & $213.12 \pm 1.12$ & $219.53 \pm 0.62$ & $220.40 \pm 0.53$ \\
\hline Group C & $195.36 \pm 0.63$ & $203.43 \pm 0.24$ & $208.16 \pm 1.96$ & $212.15 \pm 1.09$ & $217.19 \pm 0.71$ \\
\hline
\end{tabular}

intervillar spaces is composed of surface absorptive cells such as enterocytes, goblet cells, and diffuse neuroendocrine system (DNES) cells that produce hormones. The enterocytes are tall cells with basally located oval nuclei and the apical surface of each displays brush border (Figs. 1a, b). The electron micrograph of surface enterocytes show many microvilli whose tips are covered with thick glycocalyx. The actin core of the microvilli is anchored into the actin and intermediate filaments of the cell web. The cytoplasm of surface absorptive cells is rich in organelles, especially mitochondria, smooth endoplasmic reticulum (SER), rough endoplasmic reticulum (RER), and Golgi apparatus. The lateral cell membranes of these cells form desmosomes and gap junctions with adjacent cells (Figs. 1c, d).

Goblet cells are unicellular glands. The duodenum possesses the smallest number of goblet cells (Fig. 1b). An electron micrograph of the goblet cell shows the nucleus to be typically highly condensed, the distended apical cytoplasm containing a dense aggregation of mucin granules combined with water to form a viscid secretion called mucus. The cytoplasm is also packed with RER and a few mitochondria (Fig. 1e). Paneth cells, located in the basal portion of the crypts, are exocrine cells with large eosinophilic and apical secretory granules. The electron micrograph of these cells displays a welldeveloped Golgi apparatus, a large complement of rough endoplasmic reticulum, numerous mitochondria, and large apical secretory granules housing a homogeneous secretory product (Fig. 1f). Each villus possesses a core of loose connective tissues that extends from the lamina propria and contains fibroblasts, smooth muscle fibers, lymphocytes, plasma cells, fenestrated capillaries, andcenters a lymphatic capillary called lacteal.

The lining of the duodenum of rats in group B, shows a series of permanent folds, consisting of mucosa cells, glycocalyx of enterocytes, and goblet cells filled with mucin (Figs. 2a, b). The electron micrograph of the apical end of each enterocyte displays a prominent ordered region called the striated or brush border. In the terminal web, it is integrated into the cytoskeleton of the cell body. Deeper in the cell, microfilaments and microtubules are readily identified. An increase in the number of mitochondria, lysosomes, RER, and vesicles has been seen (Fig. 2c). The electron micrograph of a horizontal section through the duodenal epithelium demonstrates several important 


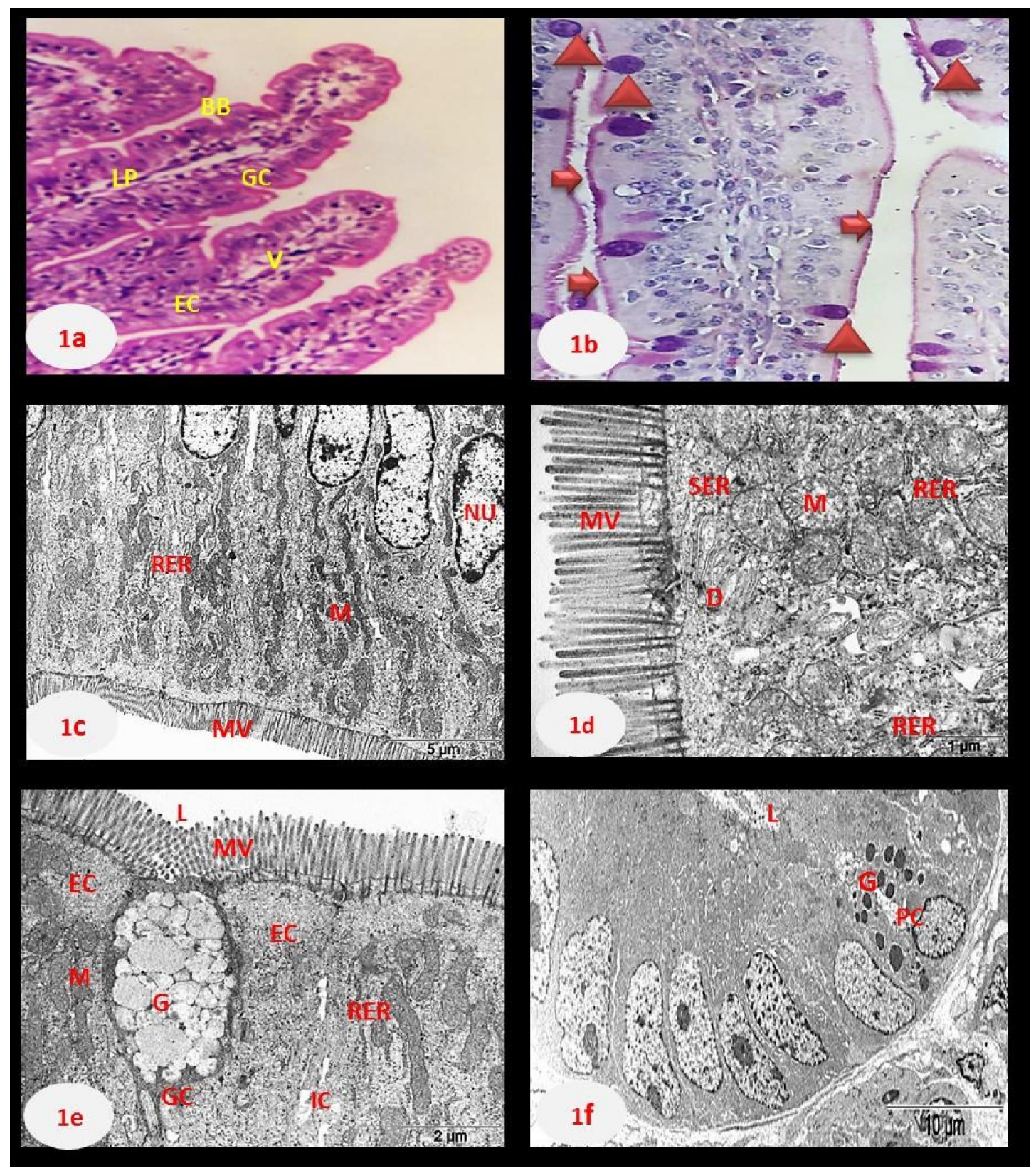

Figs. 1 a, b: Light micrograph of duodenal mucosa of control rats (group A) stained by H\&E and carbohydrate staining with PAS methods. 1 a: displaying the simple columnar epithelium covers intestinal villi (V) consists lamina propria (LP) and mainly of the tall absorptive enterocytes (EC), the apical ends of these cells showed brush border (BB) of microvilli along with the mucus-secreting goblet cells (GC). X1000. 1b: showing a strong PAS positive reaction in the goblet cells (arrow heads) and brush border (arrows) that covered by a coating of glycoproteins. X1000. 1 c, d: A higher magnification of individual microvilli of enterocytes are better seen and the striated appearance of the border is apparent. TEM show microvilli (MV) and densely packed mitochondria (M) of absorptive enterocytes with rounded nuclei (NU), rough endoplasmic reticulum (RER), smooth endoplasmic reticulum (SER) and desmosomes (D). 1e: at higher magnification individual microvilli (MV) of enterocytes (EC) are better seen and goblet cell (GC) appearance of the granules (G) are apparent and intercellular clefts (IC). 1f : Also note secretory granules (G) which consist of proteins of high electronic density surrounded by a halo of low electronic density of polysaccharide near to the lumen (L) can be distinguished in the Paneth's cell (PC). 


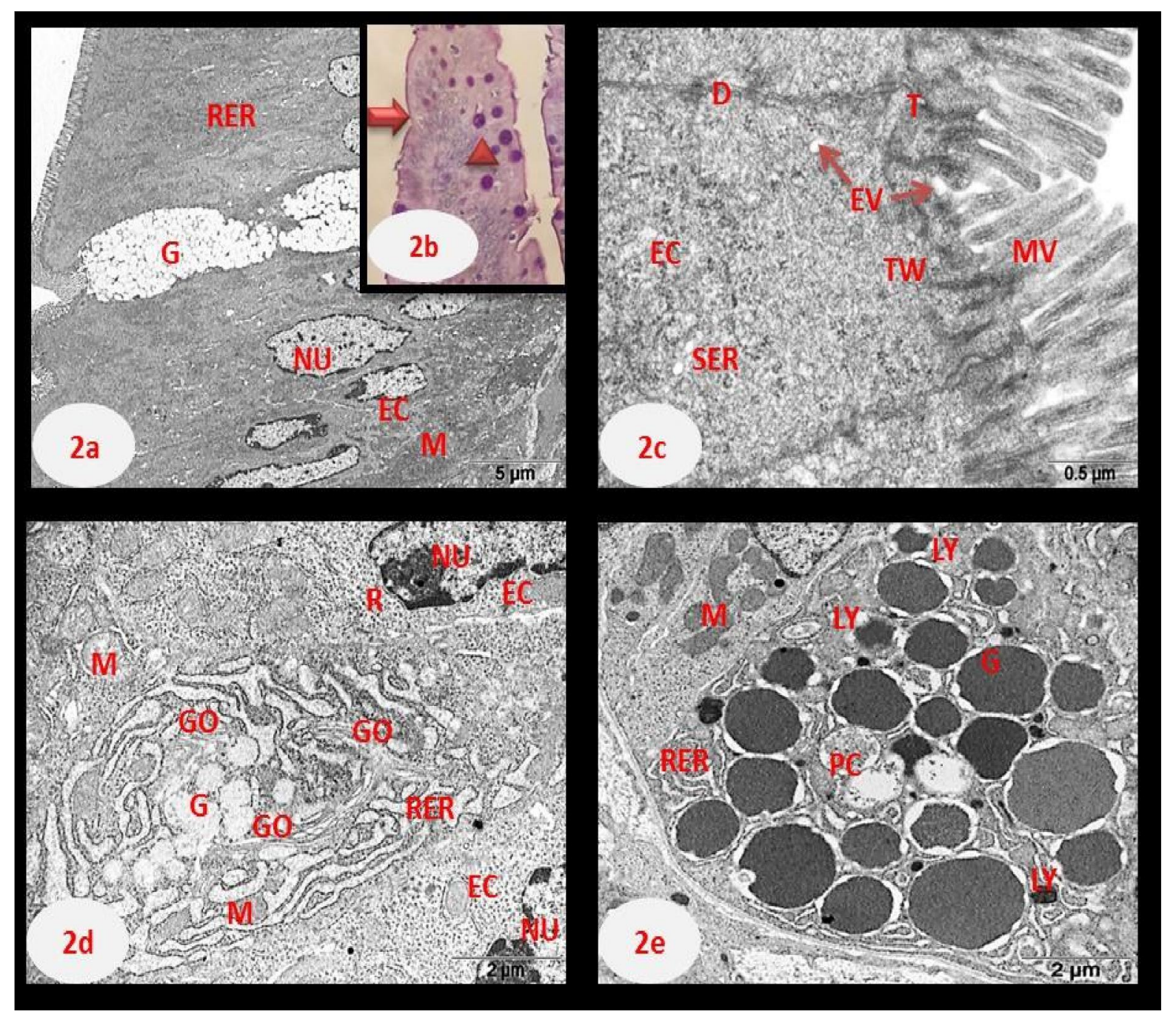

Figs. 2 a-d: Electron micrograph of duodenum from rats treated with aqueous extract of seeds Carica papaya $1 \mathrm{mg} /$ $\mathrm{kg}$ (group B). 2a : showing the enormous number of microvilli (MV), and mitochondria (M) are particularly abundant within enterocytes (EC), rough endoplasmic reticulum (RER), nuclei (NU), goblet cell and its secretion granules (G). 2b : the glycocalyex of the enterocytes (arrow) and goblet cells filled with mucus (head arrow). PAS. X1000. 2c : shows enterocytes (EC), microvilli (MV) usually prominent. In the terminal web (TW) it becomes integrated into the cytoskeletal of the body of the cell and endocytosis vesicles (EV) are seen between the basal microvilli. Smooth endoplasmic reticulum (SER) is seen deeper in the plasmic. Also shows the tight junction (T) and desmosome (D). 2d : In the central area, there is a goblet cell containing several mucin-containing granule (G). Adjacent to the mucin granules there are three Golgi apparatuses (GO) with plentiful rough endoplasmic reticulum (RER), features typical of secretory cells. Occasional mitochondria (M) are also seen surrounding the goblet cells are a number of enterocytes (EC) which contain large number of free ribosomes (R) and note nuclei (NU). 2e :Electron micrograph of Paneth cell (PC) showing the large round granules (G), rough endoplasmic reticulum (RER), and lysosomes (LY) in the cytoplasm. 


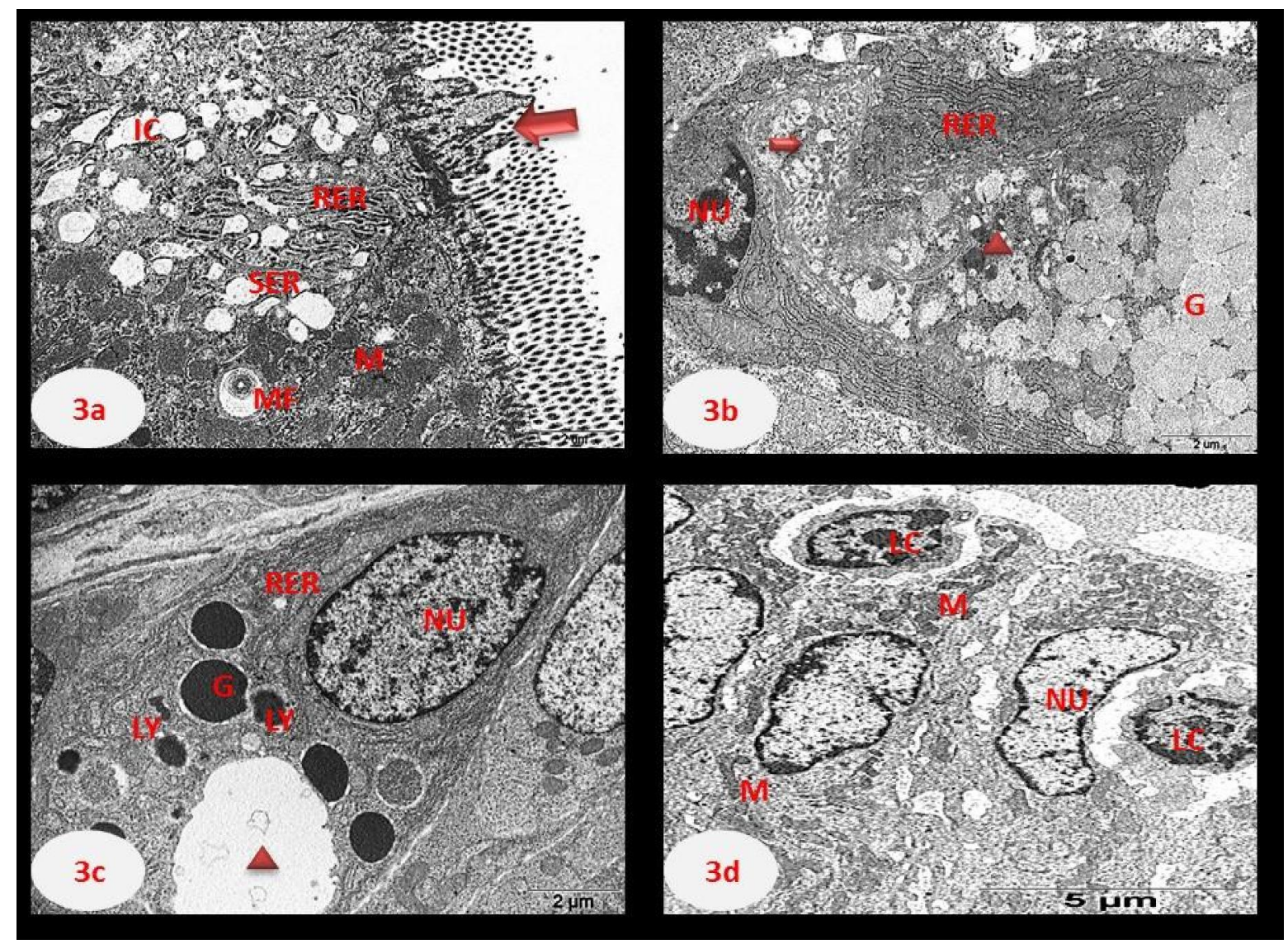

Figs. 3 a-d: Electron micrograph of duodenum from rats treated with ethanolic extract of seeds of Carica papaya $1 \mathrm{mg} / \mathrm{kg}$ (group C). 3a: shows deformed microvilli (arrow), extensive lateral inter digitations between two adjacent cells expansion of the intercellular (IC), an increase in the electronic density of mitochondria (M), and distribution of RER. Also seen myelin figure (MF). 3b: showing a goblet cell opening into the lumen. The cell is almost depleted of mucous granules (G); only few electron dense mucous granules are seen (head arrow), the cytoplasm contains dilated (RER) cisternae, cytoplasmic degeneration (arrow) and condense chromatin of nuclei (NU). 3c: showing parts of a Paneth cell containing nuclei (NU), dilated (RER), lysosomes (LY) and cytoplasmic vacuolations (head arrow). 3d: high content of chromatin in the nucleus with irregular nuclear membrane(NU), distortion of mitochondria (M), also note increased number of lymphocytes (LC) in the inter cellular clefts between enterocytes.

features in the central area such as a goblet cell containing several mucin-containing granules. Adjacent to the mucin granules, three Golgi apparatus and plentiful rough endoplasmic reticulum and mitochondria are observed. Surrounding the goblet cells, a number of enterocytes with less prominent RER and a large number of free ribosomes and mitochondria are observed (Fig. 2 d). Paneth cells, located in the basal portion of the intestinal crypts below the stem cells, are exocrine cells with large eosinophilic secretory granules in their apical cytoplasm (Fig. 2e). The electron micrographs of this cell display a well-developed Golgi apparatus, a large complement of RER, numerous mitochondria, and large apical secretory granules housing a homogeneous secretory product.

The histological and ultrastructural structure of the duodenum from rats treated with ethanolic extract of papaya seeds (Group 
C) shows no similarity in the shape, size, and number of the microvilli. Some of the microvilli appears to be swollen and joint together (Fig. 3 a). Goblet cells open into the lumen and have apical microvilli that extend towards the lumen and basal nuclei. Their cytoplasm mostly contains mucous with only a few electron-dense mucous granules, dilated RER cisternae, and atrophic nuclei. In the histological examination of goblet cells, dilation of RER and residual bodies are observed (Fig. 3 b). Furthermore, the cytoplasm of Paneth cells is filled with large spherical granules surrounded by clear halos. Most of the granules are electron-dense, and RER and lysosomes are also seen (Fig. 3 c). Lymphocytes are found in the intercellular clefts between enterocytes (Fig. $3 \mathrm{~d}$ ).

\section{Discussion}

Phytochemicals are natural food which contain an active group of compounds, classified according to their chemical composition into phenolic acids, flavonoids, tannins, and coumarins (Lu and Jiang, 2012). The useful and good health effects of flavonoids and polyphenols are due to their antioxidant activities against different oxidative stress injury and decrease heavy metals poisoning (Christen and Cuendet, 2012). Earlier, many research works were coordinated to explore the capacity of various natural food products to save and protect cells against cancer-inducing agents, with a final target to improve natural food products with protective feature against diseases (Rajput and Mandal, 2012). Several kinds of vegetables and fruits as papaya, pomegranate and seaweed extracts have been recognized as a beneficial source of phytochemicals (flavonoids and polyphenols compounds) and classified as a bioactive compound (Albini et al., 2012).

In this study, no significant differences were noticed in the body weight gain between control and treated groups, perhaps due to the same total caloric intake, micronutrients or taste choice in animals. Behavioral changes were not observed during the study as animals moved freely within the cages. All rats (both control and treated groups) survived till the end of the experiment.

The lining of the duodenum of animals in group B, showed a series of permanent folds, consisting of mucosa cells. These fold projections are covered by enterocytes and have interspersed goblet cells. There is also an enormous number of fold and microvilli which increase the surface area. The goblet cell as seen in conventional light microscopy is actually an artifact of preparation whereby water is taken up by the granules that consequently expand and compress the surrounding cytoplasm. Moreover, the glycocalyx coat not only protects the microvilli from autodigestion but also has enzymatic components that serve in the terminal digestion. Enterocytes were tightly bound near their luminal surface by junctional complexes that prevent direct access of luminal contents into the intercellular spaces and hold the epithelium together. In addition, the tight junctions prevented the passage of material via a paracellular route to or from the lumen of the gut. An increase in the number of mitochondria, reflecting the high energy of such processes. Paneth cell granules contain lysosome, phospholipase A2, and hydrophobic peptides called defensins, all of which bind and break down membranes of microorganisms and bacterial cell walls. Moreover, the Paneth cells play an important 
role in innate immunity and regulating the microenvironment of the intestinal crypts. The electron micrographs of this cell display a well-developed Golgi apparatus, a large complement of RER, numerous mitochondria, and large apical secretory granules housing a homogeneous secretory product. A recent study confirmed that feeding of an aqueous extract of $C$. papaya did not cause toxicity in rats (Harlim and Abdullah, 2011).

The histological and ultrastructural structure of the duodenum of rats treated with ethanolic extract of papaya seeds (group C) showed no similarity in the shape, size, and number of the microvilli. Some of the microvilli appeared to be swollen and joint together. A disturbed cell architecture with a marked widening of the intercellular space was also seen in myelin figures because of uncompleted autolysis. However, the cells were still bound to each other. Moreover, the damages in the mitochondria may be attributed to the hyperactivity of the enzymes, which was a response to the change elicited by the treatment. It also affected the membrane enzymes and caused an increase in the permeability of the mitochondrial membrane. The electron micrograph of a crypt base of the rat duodenum demonstrating a Paneth cell showed a decrease in Paneth cell secretion. This may be due to the degeneration of glands lining the cells and exudation of blood fluids. Lymphocytes were found in the intercellular clefts between enterocytes where they play an important part in the immunological defense of the tract. The cellular infiltration of the lymphocytes, which produce anti-toxins and accelerate cell healing, could be a sign of inflammation. It has been reported that bone marrow cell count, white blood cell count, especially increased the activity of macrophages and splenocyte count in rats treated with Carica papaya (Jayasinghe et al., 2107).

\section{Conclusion}

Our results clearly showed that feeding aqueous extract of $C$. papaya seeds did not cause gross or histopathological changes in the test group, although some changes were detected in duodenal mucosa treated with the ethanolic extract. This might be due to either the ethanolic extract fed to the rats or some other unknown reason. Present study suggests that the oral administration of $C$. papaya seeds extract may not cause acute toxicity in the rat model.

\section{References}

Akah P A, Akunyili DN and Egwuatu CN. (2002) Investigations on the analgesic and antipyrectic activities of aqueous extract of Carica papaya leaves. Nig. J. Neurosci. 5: 29-34.

Albini A, Tosetti F, Li VW, Noonan DM and Li WW (2012) Cancer prevention by targeting angiogenesis. Nat. Rev. Clin. Oncol. 9: 498-509.

Amazu, LU, Azikiwe CCA, Njoku CJ, Osuala FN, Nwosu PJC, Ajugwo AO and Ajugwo AO and Enye JC. (2010) Antiinflammatory activity of the methanolic extract of the seeds of Carica papaya in experimental animals. Asian Pacific J. Tropical Med. 3: 884-886.

Anaga A and Onehi E. (2010) Antinociceptive and antiinflammatory effects of the methanol seed extract of carica papaya in mice and rats. Afr. J. Pharm. Pharmacol. 4:140-144.

Anthony L. Mescher. (2017) Junquiere's Basic Histology: Text and Atlas. 14th ed. The McGraw-Hill Companies, Inc. USA, pp 323-334.

Christen P and Cuendet M. (2012) Plants as a source of therapeutic and health products. Chimia (Aarau) 66: 320-323.

Euis J, Yunita P, Tri M and Ajeng D. (2015) Antifertility compound from the seeds of Carica papaya. Procedia Chem. 17: 66- 69.

Harlim S and Abdullah N. (2011) Study of acute toxicity 
of Carica papaya leaf extract in rats. J. Med. Plants Res. 5: 1867-1872.

Harsh M. (2013) Pathology practical book: . $3^{\text {rd }}$ Edition, Jaypee Brothers Medical Publishers.

Hasimun P and Suwendara GIE. (2014) Analgetic activity of papaya (Carica papaya L.) leaves extract. Procedia Chem. 13:147- 149.

Jason D, Marrow L and Jackson R. (2001) Lipid-derived autacoid, eicosanoids, and platelet-activating factor. Goodman and Gilman's: The phamacological basis of therapeutics. New York: McGraw-Hill, Medical Publishing Division, USA, pp .9-680.

Jayasinghe CD, Gunasekera DS, De Silva N, Jayawardena KKM and Udagama PV. (2017) Mature leaf concentrate of Sri Lankan wild type Carica papaya Linn. modulates nonfunctional and functional immune responses of rats. BMC Complement Altern. Med. 17: 230-238.

Klatt MD and Edward C. (1951) Robbins and Cotran Atlas of Pathology-3 ${ }^{\text {rd }}$ Edition, Elsevier.

Kumar V, Abbas KA, Faust NO and Mitchell RN. (2007) Robbins Basic Pathology, $8^{\text {th }}$ Edition, Elsevier.

Leslie P and James L. (2007) Color textbook of histology, $3^{\text {rd }}$ Edition, Saunders.

Lohiya NK, Pathak N, Mishra PK and Manivannan B. (1999) Reversible contraception with chloroform extract of Carica papaya Linn. seeds in male rabbits. Reprod. Toxicol. 13: 59-66.

Lohiya NK, Manivannan B and Garg S. (2006) Toxicological investigations on the methanol subfraction of the seeds of Carica papaya as a male contraceptive in albino rats. Reprod. Toxicol. 22: 461-468.

Lu Q and Jiang JG. (2012) Chemical metabolism of medicinal compounds from natural botanicals. Curr. Med. Chem. 19:1682-1705.

Musa KY, Abdurahman EM, Shok M, Agunu A and Musa H. (2005) Acute toxicity studies of ethanolic extract of Dyschoriste perottetii Nees (Acanthaceae) in mice. Nig J. Pharm. Res. 4: 28-33.

Nwaehujor CO, Ode JO, Ekwere MR and Udegbunamand RI.(2014) Antifertility effects of fractions from Carica papaya (Pawpaw) Linn. methanol root extract in male Wistar rats. Arabian J. Chem, 7: 4852.

Oduola T, Bello I, Idowu T, AvwioroG, Adeosun G and Olatubosun L. (2010) Histopathological changes in Wistar albino rats exposed to aqueous extract of unripe Carica papaya. North Am. J. Med. Sci., 2:234237.

Ong H, Chua S and Milow P. (2001) Ethno-medicinal plants used by the temuan villagers in Kampung Jeram Kedah, Negeri Sembilan, Malaysia. Ethano Med. 5: 95-100.

Otsuki N, Dang N, Kumagai E, Kondo A, Iwata S and Morimoto C. (2010) Aqueous extract of Carica papaya leaves exhibits anti-tumor activity and immunomodulatory effects. J. Ethnopharmacol. 127: 769-676.

Owoyele B, Olubori M, Adebukola A, Funmilayo A and Soladoye A. (2008) Anti-inflammatory activities of ethanolic extract of Carica papaya leaves. Inflammopharmacology 16:168-73.

Prabhu V, Nalini G, Chidambaranathan N and Sudarshan S. (2011) Evaluation of antiinflammatory and analgesic activity of Tridax procumbens Linn. against formalin, acetic acid and CFA induced pain models. Int. J. Pharm. Pharm. Sci. 3:126-30.

Rajput S and Mandal M. (2012) Antitumor promoting potential of selected phytochemicals derived from spices: A review. Eur. J. Cancer Prev. 21:205-215.

Sinhalagoda L, Susiji W, Roshitha N, Rajapakse P and Senanayake A. (2013) Does Carica papaya leafextract increase the platelet count? An experimental study in a murine model. Asian Pac. J. Trop. Biomed. 3: $720-724$.

Tarun VJ and Prashar Y. (2015) A review on medicinal properties of Carica papaya Linn. Asian Pac. J. Trop. Dis. 5: 1-6.

Trease GE and Evans WC. (1983) Textbook of Pharmacognosy. 12 $12^{\text {th }}$ Edition, London: Bailliere Tindall, pp .102.

Wabo Pone J, Ngankam JDN, C.FB. Bilong Bilong CF and Mibida M. (2011) A comparative study of the ovicidal and larvicidal activities of aqueous and ethanolic extracts of pawpaw seeds Carica papaya 
(Caricaceae) on Heligmosomoides bakeri. Asian Pac. J. Trop. Med. 4: 447-450.

Wallace J. (2008) Prostaglandins, NSAIDs, and gastric mucosal protection: why doesn't the stomach digest itself? Physiol. Rev. 88: 1547-1565.
Young B, O'Dowd G and Woodford P. (2014) Wheater's functional histology. $6^{\text {th }}$ Edition, Churchill Livingstone. 